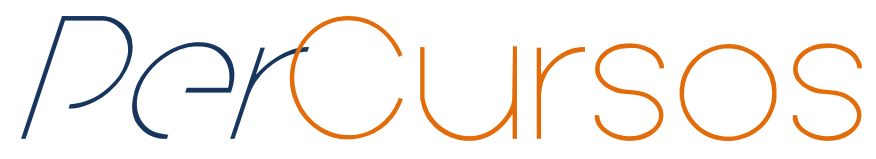

\title{
Geração de trabalho e renda: a trajetória de três grupos na relação com a Universidade e o Poder Público Municipal
}

\begin{abstract}
Resumo
Os Empreendimentos de Economia Solidária (ES) apresentam-se como alternativa para os excluídos do emprego formal, mas há vários entraves no seu funcionamento. Objetiva-se compreender as representações sobre os processos vivenciados na gestão do trabalho em três grupos de ES. Pautouse em abordagem qualitativa e coleta de dados: análise documental, observação participante e entrevistas. Constatou-se que: a incorporação dos princípios da ES nos grupos era um desafio em poucos momentos contemplado; havia falta de clareza acerca das relações com o Poder Público; e havia carência de construção efetiva de metas e projetos coletivos.
\end{abstract}

Palavras-chave: Economia Social. Programa de Geração de Emprego e Renda (Brasil). Autogestão.

\author{
Ana Paula Leivar Brancaleoni \\ Doutora em Psicologia pela \\ Universidade de São Paulo - USP. \\ Professora da Universidade \\ Estadual Paulista "Júlio de \\ Mesquita Filho" - UNESP. \\ Brasil \\ anapaulabrancaleoni@gmail.com
}

\section{Ana Claudia Giannini Borges}

Doutora em Sociologia pela Univ.

Estadual Paulista - UNESP.

Professora da Universidade

Estadual Paulista "Júlio de

Mesquita Filho" - UNESP

Brasil

ana.giannini@unesp.br

\footnotetext{
Para citar este artigo:

BRANCALEONI, Ana Paula Leivar; BORGES, Ana Claudia Giannini. Geração de trabalho e renda: a trajetória de três grupos na relação com a Universidade e o Poder Público Municipal. Revista PerCursos, Florianópolis, v. 19, n.41, p. 258- 288, set./dez. 2018.
}

DOI: $10.5965 / 1984724619412018258$

http://dx.doi.org/10.5965/1984724619412018258 


\title{
Generating employment and income: the trajectory of three groups in relation to the University and the Municipal Government
}

\begin{abstract}
The Enterprises of Solidary Economy (SE) configure themselves as an alternative for people who are excluded from formal employment, even though these Solidary Enterprises faces several obstacles in their operations. This article aims to understand the representations of experienced processes in work management into three groups of Solidary Economy. The survey was conducted in a qualitative approach. Data collection instruments were: document analysis, participant observation and interviews. The results of the research are: the incorporation of the principles of ES in groups was a challenge in a few moments contemplated; there was a lack of clarity about the relations with the government; and there was a lack of effective on building goals and collective projects..
\end{abstract}

Keywords: Social Economy. Generating Programmes of Employment and Income (Brazil). Self-Management. 


\section{Introdução}

As transformações socioeconômicas, no Brasil, principalmente a partir dos anos de 1990, com a adoção das políticas neoliberais, resultam em um panorama em que a garantia da dignidade humana é um pressuposto a ser perseguido. Pois, mesmo que o Estado brasileiro não tenha se configurado em um modelo de bem-estar social, o mesmo teve sua atuação diminuída na regulação da relação capital-trabalho e no atendimento das demandas sociais. Neste contexto, destaca-se também a visão homogênea de globalização, propiciando participação no processo acelerado de revolução tecnológica e de competitividade. Contraditoriamente, esta, ao mesmo tempo em que propicia inserção, ocasiona exclusão, visto que uma parcela da população vivencia condição de exploração e exclusão do mercado de trabalho (SANTOS, 2001). Assim, acentuam-se as transformações na organização do trabalho, com maior flexibilização da produção, o que precariza e diminui a qualidade de vida do trabalhador (ANTUNES, 2002). Essa condição amplia-se com a alteração da Consolidação das Leis Trabalhistas - CLT (BRASIL, 2017).

Igualmente, Nascimento (2000) destaca que essa predominância pelo ideário internacionalizante, global e neoliberal amplifica a dependência dos países ao funcionamento econômico, produtivo e financeiro internacional que, juntamente, com a redução da atuação do Estado, dentre elas, quanto às políticas sociais, resultam de forma geral no aumento da estagnação da sua estrutura, trazendo prejuízo à mobilidade social e, com isso, maior desigualdade. Dessa forma, tem-se a nova exclusão social que, de acordo com Nascimento (1994, 2000), depende, ao mesmo tempo, de aspectos econômicos, culturais e sociais, que se consubstanciam com a expulsão de sujeitos do mundo de trabalho e dos direitos sociais, com o não reconhecimento ou negação dos direitos destes e com o rompimento de vínculos societários e comunitários.

Assim, a Economia Solidária passa a ser um possível caminho de democratização do acesso ao trabalho e à renda e de combate à desigualdade social. A Economia Solidária ganha força com a institucionalização da Secretaria Nacional de Economia Solidária (Senaes) em 2003, pelo governo do presidente Luiz Inácio Lula da Silva (SINGER, 2014). 
A Economia Solidária pauta-se na lógica de que o homem e sua dignidade estão acima do lucro e do capital, o que aparece como possibilidade de sobrevivência das camadas da população excluídas do mercado formal de trabalho. É uma concepção construída sob princípios, como: prática da autogestão e processos decisórios democráticos; relações sociais de cooperação entre pessoas e grupos; e horizontalidade nas relações sociais em geral (COUTINHO et al., 2005). No Sistema Nacional de Informações em Economia Solidária (SIES), a Economia Solidária é um conjunto de atividades econômicas organizadas e realizadas por trabalhadores, a partir dos princípios de cooperação, autogestão, solidariedade e ação econômica (BRASIL, 2006), ou seja, em que haja a participação de todos, com vistas à geração de trabalho e renda (SINGER, 2008).

Vale ressaltar que a autogestão se inviabiliza quando um grupo de assessores ou consultores, externo ao empreendimento, passa a tomar as decisões em substituição ao coletivo que deveria geri-lo (VERARDO, 2005). Portanto, os processos decisórios devem necessariamente ser democráticos e não tecnocráticos, desde a constituição do grupo, assim como ao longo de todo o seu desenvolvimento.

Esclarece-se que a Economia Solidária não pode: ser uma política compensatória ou saída para a falta de emprego e renda aos 'excluídos'; e se restringir a um setor à parte, como sendo própria do "terceiro setor". Ao contrário, deve se pautar nas dimensões econômica, política, social e cultural e constituir-se em um processo de transformação social, em que os preceitos de solidariedade, cooperação e autogestão sustentem todas as relações (CASTANHEIRA; PEREIRA, 2008).

Ressalta-se que, para trabalhar em um empreendimento de economia solidária (EES), os sujeitos devem se "reeducar", ou seja, desenvolver olhares, pensamentos e práticas distintos daqueles atrelados à sociedade de mercado. Contudo, o trabalhador, inserido nesse tipo de EES, dificilmente consegue romper rapidamente com o modo de produção ao qual estava acostumado até então, reproduzindo, por vezes, as velhas práticas capitalistas, ainda que as mesmas não resultem em êxito para o coletivo (SINGER, 2008). 
É relevante indicar que há estudos apontando as dificuldades vivenciadas por esses trabalhadores, nos seus processos de produção e gestão, desde a organização do trabalho, quanto aos processos de geração de tecnologias sociais e políticas públicas que atuem no desenvolvimento socioeconômico desses agentes sociais, promovendo inclusive o crescimento do número de consumidores críticos e conscientes.

O Ministério do Trabalho e do Emprego pondera as dificuldades encontradas pelos EES para se manterem no mercado, entre as quais, têm-se: comercialização, acesso ao crédito, assistência e formação. No atlas de Economia Solidária (BRASIL, 2013), destaca-se que: $32 \%$ dos EES não conseguem remunerar seus sócios, o que é reafirmado quando apontam que um dos "principais desafios" é obter renda adequada para os sócios (18\%); e 16\% apresentam dificuldade na obtenção de viabilidade econômica, 14\% em manter o grupo unido e 11\% em realizar gestão participativa e autogestionária (BRASIL, 2013).

Assim, as motivações para a presente pesquisa originaram-se da experiência, ao longo de anos, na atuação em projeto de extensão que tem por objetivo a geração de trabalho e renda, junto a grupos da sociedade civil que vivenciam situação de vulnerabilidade social, sejam esses formalizados ou não. A condição de três grupos, em especial, convidou-nos a um maior aprofundamento. Isso porque, ao longo da atuação no Projeto de Extensão, foram estes que despertaram mais inquietações.

Com isso, objetiva-se analisar a dinâmica de três Grupos de geração de trabalho e renda que foram assessorados por um projeto de Extensão Universitária, com especial enfoque para as percepções dos agentes acerca: dos motivos para a aproximação com a Economia Solidária; das relações estabelecidas com o Poder Público e outros agentes externos; e da apropriação dos princípios da Economia Solidária pelos grupos.

\section{Trajetória metodológica}

Utilizou-se a abordagem qualitativa, pois esta tem como principal característica, segundo Alves (1991), a visão contextualizada dos fenômenos, a abordagem indutiva e a investigação naturalística. 
A pesquisa teve como recorte de análise dois grupos (Horta e Associação de catadores) localizados em uma cidade de cerca de 70 mil habitantes e, outro (Associação de Artesãs), em uma cidade de aproximadamente 700 mil habitantes, ambas no interior de São Paulo. Os grupos da Horta e Associação de Artesãs já haviam se dissolvido no momento em que a proposta da presente pesquisa foi apresentada. A escolha por esses dois grupos se deve ao fato de que a análise dos motivos de ruptura deles, com a proposta coletiva de geração de trabalho e renda, também pode trazer elementos para a compreensão de entraves e fracassos vivenciados por empreendimentos dessa natureza.

Os instrumentos de coleta de dados utilizados foram: análise documental de cadernos de registros dos grupos, livros ata de reuniões, estatutos e regimentos, diários de campo de observação participante e documentos do Poder Público Municipal referentes aos empreendimentos; entrevistas semiestruturadas com representantes dos três grupos de economia solidária; observação participante, realizada ao longo de dois anos e sistematicamente registrada em diário de campo. As entrevistas foram gravadas e integralmente transcritas, respeitando-se a forma de expressão dos sujeitos.

Hammersley e Atkinson (1992) destacam que a coleta e análise dos dados se dá de forma simultânea. Segundo Ludke e André (1986), a análise dos dados, que é realizada desde o início da pesquisa, se intensifica no final. Na análise preliminar, o problema pesquisado foi sendo delimitado e os dados analisados foram servindo para indicar o caminho a seguir, possibilitando a definição de categorias que foram utilizadas na análise. Estas categorias surgem do discurso dos sujeitos envolvidos e das observações, sem serem pré-definidas de forma rígida, ou seja, sendo construídas com análise do material obtido e da teoria (FRANCO, 2002). Levando-se isso em conta, e tendo por base os objetivos da pesquisa, foram criadas as categorias de análise (fase preliminar).

A análise final considerou as categorizações construídas até aquele momento. Essa etapa se constituiu na tentativa de explicar a realidade estudada, tendo por base a teoria, confrontando-a com os dados obtidos, sempre buscando levar em conta o contexto social mais amplo, como apontam Ludke e André (1986). 


\subsection{Histórico dos grupos analisados}

Horta

A Horta foi um projeto idealizado por um médico (do sistema municipal de saúde) que, a partir dos problemas de seus pacientes do ambulatório de DST/AIDS (doenças sexualmente transmissíveis), identificou a dificuldade destes em aderirem ao tratamento e os problemas financeiros e sociais decorrentes da falta de trabalho e da pouca renda. Esse projeto foi premiado (concurso da indústria farmacêutica) e possibilitou recurso para o pagamento de "bolsas" a alguns participantes, e compra de equipamentos e insumos.

O projeto objetivava promover e desenvolver a autonomia e a autogestão dos pacientes, através do processo de planejamento e implementação de uma horta urbana. E, com isso, propiciar acompanhamento terapêutico mais próximo, com cuidado físico e psicológico contínuo, além da ressignificação da identidade social desses pacientes.

O grupo contou com pessoas que participaram desde o seu início, visto que algumas desistiram, e outras que entraram ao longo de seu desenvolvimento. A participação no projeto podia ocorrer com membros: efetivos que recebiam uma "bolsa", após triagem socioeconômica e seleção daqueles que apresentavam maior dificuldade financeira; e voluntários que colaboravam com o projeto, recebendo um valor de custeio para cobrir os gastos realizados, com material ou combustível em prol da horta. É importante destacar que os recursos da premiação se esgotaram após um ano do início do projeto. A partir desse momento, a única forma de vinculação passou a ser voluntária, sendo que a renda deveria ser exclusivamente da comercialização dos produtos da horta.

O recurso do prêmio e de doações e o vínculo com o ambulatório facilitaram a constituição inicial do grupo e a obtenção da estrutura física (dois terrenos vizinhos cedidos pela Prefeitura Municipal) para a realização das atividades. A vinculação com a Prefeitura Municipal e ao Ambulatório DST/AIDS colaborou para o estabelecimento de relações de sentimento de dependência dos integrantes frente aos profissionais da saúde, Poder Público e agentes externos. 
Os membros da Horta eram pessoas marcadas por processos de exclusão e que vivenciaram relações de caráter assistencialista com o poder público e outras instituições. Com o término do subsídio, o grupo permaneceu por mais dois anos subsequentes. Em alguns períodos (de oitenta nove dias), foram remunerados pela Prefeitura Municipal, como trabalhadores da frente de trabalho. Por fim, o grupo acabou se dissolvendo.

\section{Grupos de mulheres artesãs}

O nascimento desse grupo ocorreu a partir da atuação de um Centro de Defesa de Direitos Humanos (CDDH) existente na cidade. A atuação deste junto ao grupo se deu em atendimento ao pedido de um pároco de uma igreja, situada em bairro periférico do município, que identificava a necessidade de promover acesso ao trabalho e possibilitar a geração de renda para a comunidade local.

Assim, fez-se o diagnóstico social do bairro, que constatou elevado número de mulheres com aptidão para o artesanato e que precisavam complementar a sua renda. Com isso, o CDDH organizou, com a comunidade, reuniões semanais na paroquia local, a fim de trocar experiências e saberes sobre a produção artesanal (crochê, bordado, costura). Nas reuniões, as mulheres perceberam que essa atividade poderia ser uma forma de geração de renda, se a produção fosse vendida. Assim, buscaram-se vias de comercialização dos produtos e auxílio técnico para a gestão deste novo empreendimento.

As primeiras vias de comercialização foram em bingos e bazares no próprio bairro. No entanto, após 18 meses, com o apoio do $\mathrm{CDDH}$, o grupo conseguiu captar recursos financeiros junto a um Fundo, vinculado a uma entidade social sem fins lucrativos, que financiava iniciativas e projetos em prol da emancipação de mulheres e desenvolvimento de seus grupos, bem como de outras mulheres, de suas famílias e da comunidade.

Com esse recurso, o grupo investiu na abertura de uma loja na região central do município, onde passaram a comercializar sua produção. A gestão da loja era definida pelo grupo de mulheres, com o auxílio do $\mathrm{CDDH}$ (núcleo multiprofissional) e de estudantes do curso de administração de Universidades Públicas. Os encontros entre as artesãs e o grupo de apoiadores aconteciam semanalmente, quando se discutiam a 
organização e gestão da loja, assim como as dificuldades e formas de superação.

Devido à dificuldade de deslocamento do bairro onde residiam até o local de trabalho, as mulheres foram desenhando outros projetos pessoais. Assim, os encontros entre as mulheres passaram a ser raros, pois havia um rodízio entre elas, para manter a loja aberta. Por fim, as atividades da loja foram encerradas, sendo que, entre as três últimas integrantes, uma concluiu curso técnico em enfermagem e se empregou, outra conseguiu emprego e uma terceira se mudou de cidade.

\section{Associação de catadores}

No ano de 2001, a gestão municipal decidiu reunir pessoas desprovidas de trabalho e renda para que, de forma coletiva, trabalhassem com materiais recicláveis na cidade. Essa ação estava incluída na Política Pública de Economia Solidária do município.

No início, os trabalhadores possuíam vínculo formalizado com a Prefeitura Municipal, recebendo um valor mensal fixo pela realização do trabalho, reconhecido como salário, o que os configuraria como funcionários municipais. Essa iniciativa estava na agenda da Economia Solidária do município, que formalizou a cooperativa, no entanto não estimulou a apropriação desta e dos princípios da Economia Solidária pelo grupo. Assim, frente à mudança de governo, com novas eleições municipais, e o desconhecimento, por seus trabalhadores, dos procedimentos formais e legais para manter uma cooperativa, fez com que esta chegasse à condição de irregularidade.

O abandono do Poder Público Municipal motivou o grupo a procurar interlocutores e formas de ajuda externa com a Universidade. Nesse processo, o grupo mudou sua configuração jurídica para Associação, pois, naquele momento, o número de integrantes era inferior a 20 (número mínimo para compor uma cooperativa pela legislação vigente na época). Desde então, foram apoiados por um projeto de Extensão Universitária, especialmente no que se referia à organização e gestão do grupo.

No ano de 2009, a Prefeitura propôs uma nova forma de intervenção, indicando um agente externo para atuar com o grupo como requisito para a assinatura de convênio entre as partes. Esse agente acompanharia as contas, vendas e divisões realizadas na Associação, causando resistência inicial dos associados. Com o tempo, o grupo aceitou a 
proposta e a atuação dessa pessoa, bem como repassou responsabilidades que eram do grupo. Assim, observa-se a perda da clareza acerca das sobras, dos gastos e das divisões.

Nas eleições municipais subsequentes, manteve-se o governo. Contudo, este não estabeleceu um posicionamento claro frente à Associação, ocasionando incerteza no grupo. Foram sucessivas promessas não cumpridas e informações desencontradas acerca de futuras ações da gestão municipal em relação ao grupo, o que colaborou para a perda de coesão e desarticulação interna, assim como para o gradual afastamento de suas ações dos princípios da economia solidária. Dessa maneira, o grupo, mesmo mantendo-se como tal, tornou-se um coletivo enfraquecido, com pouca reflexão sobre suas ações, não se apropriando, portanto, coletivamente de seus processos de produção e gestão.

\section{Resultados}

Nesse tópico, apresentam-se os resultados do trabalho a partir dos seguintes eixos: motivos para a vinculação a empreendimentos de economia solidária; a relação do poder público e de outros agentes externos com os grupos, momento em que serão pontuadas as representações acerca das funções de cada agente; e a apropriação dos princípios da economia solidária, destacando as dificuldades enfrentadas e possibilidades de superação dos entraves.

\subsection{Motivos para a aproximação da economia solidária}

A questão da renda foi apresentada pelos membros dos grupos como o principal motivo para a vinculação à proposta de grupo e futuro empreendimento, ainda que com ênfase diferente para cada um dos coletivos.

Para a Associação de Catadores, observa-se a necessidade de trabalho e renda quase que como único motivo para vinculação inicial ao grupo, como relatado pela senhora Gilda: "Daí a gente não encontrava mais emprego e precisava comer, vestir... vim trabalhar aqui." Após a vinculação e o desenvolvimento do trabalho, passavam a defender e a afirmar que este era bom, como ilustrado na fala do senhor Claudio: “Porque o trabalho que a gente faz não é ruim, tem muito trabalho pior, o nosso não." 
Entre os membros do grupo da Horta, a questão da renda também era o principal motivo à vinculação, ainda que esta tenha sido efetivada por indicação. Destaca-se a configuração distinta desse grupo, visto que parte de seus integrantes recebiam inicialmente uma "bolsa", desde que fossem pacientes do ambulatório de infectologia da cidade e realizassem adequadamente o tratamento antirretroviral. Ressalta-se que a ideia da Horta gerar renda não partiu do grupo, mas do projeto elaborado por um médico, condição esta que favoreceu o ingresso ao grupo. A importância dessa renda é observada na fala da senhora Clara: “A nossa situação é difícil. Essa renda faz diferença mesmo.”

No grupo de mulheres artesãs também aparece a necessidade da renda, mas elas enfatizam o espaço de sociabilidade, troca e convivência, especialmente, quando se reuniam para produzir no próprio bairro. Isso é explicitado na fala da senhora Rita: "Quando a gente estava no bairro, e se encontrava todo mundo, era muito legal porque uma ajudava, ensinava e aprendia. Acho que isso era o principal motivo pra gente ficar ali junta produzindo." Como será discutido adiante, com a formação da loja há a perda desse espaço de sociabilidade e, com isso, dos motivos para permanência no empreendimento.

\subsection{O Poder Público e outros agentes externos na relação com os grupos}

\section{Poder Público Municipal e o grupo da Horta}

O Grupo da Horta, desde o início, estabeleceu uma relação com o Poder Público Municipal, porém não formalizada e sem clareza dos parâmetros que a balizariam ou das funções de cada parte. A Prefeitura disponibiliza dois terrenos vizinhos para a construção da sede e da horta, mas após os espaços de interlocução, entre ambos, se reduziram a tentativas dos membros do grupo em pedir auxílio à Prefeitura a fim de atender demandas emergenciais para sua manutenção (equipamentos, insumos, serviços). Por parte da Prefeitura, observavam-se promessas e respostas pontuais às solicitações, como relatado pela senhora Jandira: "A gente nunca sabe com o que pode contar. A gente vai tentar falar com alguém da prefeitura, sempre prometem que vão ajudar."

A inconstância na relação com a Prefeitura acentuava o sentimento de insegurança do grupo, visto que as promessas serviam como elo de manutenção da dinâmica, o que prejudicava a consolidação do grupo. Frequentemente, discursos como 
"vamos pedir para o prefeito" ou "vamos pedir para a primeira dama" surgiam no grupo, o que os distanciava da compreensão de que são sujeitos de direitos e reafirmava o ideário assistencialista. Assim, qualquer benfeitoria no projeto era tratada como "favor e bondade do governante municipal” e não como direito conquistado pelos próprios sujeitos, mantendo-se a velha política de compadrio. Baptista (2013) afirma que os sujeitos de EES não devem querer “esmola”, mas sim serem resguardados por políticas públicas, visto que são cidadãos e, portanto, sujeitos de direito. Somente via políticas públicas, que proporcionem a estruturação para haver emancipação social, dignidade e trabalho, é que se conseguirá romper com a condição assistencialista.

Dessa forma, constatava-se não só a ausência de uma Política Pública destinada à geração de trabalho e renda, nos princípios da Economia Solidária, mas a permanência de concepções de que o grupo era incapaz de se autogerir, sendo importante uma gestão externa, ou seja, a presença de alguém coordenando e ordenando o que e como deviam fazer, ferindo o princípio da autogestão. Nesse sentido, tem-se Verardo (2005) pontuando o problema de substituir as decisões tomadas de forma democrática pela tecnocrática. Esse quadro é contraditório, na medida em que se reconhece a importância do Poder Público para viabilizar os projetos de Economia Solidária, visto que estes fazem parte da Política Nacional, via Senaes (SINGER, 2014).

Outra ação da Prefeitura foi o oferecimento de cursos de formação (apostilados e organizados em dinâmicas e palestras), em parceria com o SEBRAE, a fim de fomentar o “espírito empreendedor”. Cursos que enfatizam que o sujeito deve ser autônomo e capaz de construir alternativas para superar sua condição financeira e social, independente das condições em que vive. Assim, a superação da condição de exclusão dependeria apenas de sua motivação e atuação, ou seja, do mérito do indivíduo.

Essa concepção de "autonomia" visa mais a desresponsabilização do Poder Público na geração de trabalho e renda, do que viabilizar a emancipação dos sujeitos, reforçando inclusive o caráter individualista e não os princípios preconizados pela Anteag (2005) para a formação dos trabalhadores. Os cursos não propunham um diálogo e não consideravam suas percepções e anseios, distanciando-se da realidade do grupo, como se observa na fala da senhora Rosa: "Eu fico olhando a apostila, olhando a apostila e parece 
tão bonito, mas não sei como usar aquilo nas coisas que a gente vive [...] Faço os exercícios, mas aquilo é papel e longe da vida da gente."

Nos cursos promovidos com o Governo do Estado de São Paulo, delimitava-se, inclusive, a "vocação de trabalho dos sujeitos", o que não foi considerado, visto que uma das integrantes se inscreveu no curso de informática e, no entanto, foi designada ao curso de formação em trabalhos domésticos. Isso lhe causou desagrado e resultou na decisão de não o realizar, como observado na fala da senhora Jandira: “Eu não vou fazer esse curso de trabalhos domésticos. Eu queria aprender informática, me formar. Mas me encaixaram nesse outro sem eu querer. Fiquei chateada, nem vou voltar lá."

Analisando a postura do Poder Público Municipal, pode-se chegar a dois apontamentos. O primeiro se refere à compreensão de que as ações por parte deste se sustentam pelos pressupostos psicossociais da exclusão discutidos por Guareschi (2002). Isso porque referenciam e reforçam as posturas de competitividade e subordinação no grupo. Além disso, culpabilizam os sujeitos por seu insucesso na medida em que estes são significados como "não sendo empreendedores" e incapazes para a autogestão. Além de manter os sujeitos excluídos dos saberes, visto que constroem configurações que os posicionam meramente na execução de ordens externas, demandadas por administradores "preparados para tal”. Identifica-se, ainda, uma contradição nos discursos, visto que o sujeito é entendido como autônomo no que se refere à responsabilização por sua condição social, mas, por outro lado, é entendido como incapaz de constituir experiências autogestionárias bem-sucedidas. $O$ segundo apontamento refere-se ao reforço do individualismo que, para Matheus (2000), sustenta o ideário do homem moderno e se coloca em oposição à vivência do coletivo que é tão cara à Economia Solidária.

Constata-se, portanto, que as ações do Poder Público Municipal dificultaram os processos de ruptura e superação necessários para que o grupo alcance maior autonomia para se autogerir e se tornar autossuficiente. A partir de Silva (2002), pode-se entender que essas ações têm poucas chances de sucesso quanto à adoção de novas práticas e atitudes pelos sujeitos. Pois, estes não foram considerados enquanto coletivo e nem se possibilitou processos que superassem a mera transmissão de conhecimentos técnicos. 
Com isso, a reflexão e a tomada de consciência, quanto aos aspectos fundamentais da forma como se organizam, não foram estimuladas.

\section{Poder Público Municipal e a Associação de Catadores}

Por situar-se ao lado do Aterro Sanitário Municipal, a Associação sempre manteve estreita relação com a Prefeitura Municipal e, após, com o órgão gestor do aterro que, também, presta o serviço de fornecimento de água e manutenção da rede de esgoto.

Destaca-se que ocorreu na Associação uma intervenção da Prefeitura, convencendo-os a assinar um Termo de Convênio que não os favorecia e que isentava esta de deveres junto à Associação. Além disso, observa-se a indicação de uma pessoa externa para ajudar na gestão, o que, como salientado por Verardo (2005), impacta negativamente na autogestão do empreendimento. Devido às características internas do próprio grupo (baixo grau de escolaridade, dificuldade de apropriar processos de trabalho e gestão e preferência pela heterogestão), eles não reagiram a essa imposição, abrindo mão de tarefas e funções executadas por eles, tais como: venda do material separado; realização e verificação das contas e balanços, o que era de responsabilidade do Tesoureiro e do Conselho Fiscal, segundo o Estatuto Social da Associação (elaborado coletivamente pelos associados); e a divisão das sobras entre os associados.

Constatou-se retrocesso organizativo do grupo, pois já haviam se apropriado de alguns conhecimentos e ferramentas de gestão. Com isso, o Conselho Fiscal passou a existir apenas no papel e os demais membros se posicionaram de forma passiva frente à realização das atividades de gestão, como destaca a senhora Vera: "A gente não sabe mais das contas. Mas esse senhor sabe. Ele controla e evita de ter desvios."

Com disso, estabelece-se um sentimento de paternalismo por parte dos associados com o agente externo, que passa a ser visto como "pai" e, portanto, essencial para que todo o processo de desenvolvimento da Associação se mantivesse. Essa postura era constantemente reforçada pelos agentes do Poder Público Municipal. O questionamento sobre o real papel desenvolvido por esse agente externo é rebatido, como evidenciado na fala do associado senhor Joaquim: "Ele ajuda muito a gente aqui, 
todo mundo gosta dele. Se a gente pedir as contas pra ele, ele traz. Eu não sei por que vocês ficam falando mal dele, ele é o que mais ajuda a gente."

Dessa forma, o trabalho de fiscalização e apresentação das contas para o grupo foi repassado para esse agente externo. Assim, pode-se observar que houve um processo de “desaprendizagem”, na medida em que o grupo se desapropriou de questões e saberes importantes sobre sua organização e gestão.

Essa intervenção e a falta de clareza quanto à função do Poder Público Municipal explicitam, também, a centralização das decisões em um dos associados que já apresentava liderança junto ao grupo, em detrimento da importância das decisões coletivas. Isso é identificado na fala do senhor João: "Eu não sei. Quem sabe é a presidente e é ela que decide." Esse posicionamento contribuiu para a desarticulação do grupo, logo, para o enfraquecimento da autogestão e para o entrave de seu desenvolvimento. Mesmo com o posterior afastamento desse agente externo, a relação de dependência frente a alguém se manteve na figura de uma associada que já assumia postura centralizadora e pouco democrática, divergindo dos processos decisórios democráticos (COUTINHO et al., 2005).

Ressalta-se que o Poder Público não assumiu sua responsabilidade nesse processo de perdas do aprendido e de centralização, acusando os associados de incompetência e incapacidade, como explicitado na fala de um dos representantes de uma autarquia municipal: "Aquilo é um antro. Porque o que a presidente fala eles obedecem e ela não é confiável. Assim, não tem porque colaborar com eles. Isso não vai mesmo pra frente."

\section{Poder Público e a Associação de Artesãs}

A Associação de Artesãs, localizada em outro município, não chegou a estabelecer qualquer relação com o Poder Público. Mesmo quando este foi procurado pelos agentes apoiadores, não demonstrou qualquer interesse em apoiar o Empreendimento ou em assumir a Economia Solidária como pauta de Política Pública, mesmo com a institucionalização da Senaes pelo Governo Federal em 2003 (SINGER, 2014). 


\section{Relações com outros agentes}

Merecem destaque as intervenções e atuações de Organizações Não Governamentais (ONGs) junto ao grupo da Horta e à Associação de Catadores.

No caso da Horta, no início do ano de 2010, uma nova ONG (com sede em outra cidade da região) se instalou no município. Esta tinha uma relação estreita e pouco clara com o Poder Público Municipal, visto que um de seus dirigentes ocupara cargo de confiança na gestão em questão. Assim, a Prefeitura saiu de cena atribuindo à ONG a responsabilidade de atuação com o grupo, configuração criticada, por Montaño (2002), ao destacar o papel do Terceiro Setor frente ao afastamento do Estado no atendimento das demandas sociais. Isso é evidenciando pela senhora Margarida: "Agora não é mais a prefeitura. É a ONG que vai ajudar a gente a conseguir o que a gente precisa."

Por intermédio de assistente social, há a aproximação da ONG com o grupo e esta se comprometeu a apoiá-los na resolução de problemas vivenciados no cotidiano, quanto à aquisição de insumos e serviços necessários à manutenção da horta, bem como na possibilidade de repasses financeiros (bolsas) aos integrantes. Essas medidas de caráter imediato e assistencialista foram aceitas pelo grupo, o que arrefeceu as resistências iniciais frente à aproximação desse novo agente, como destaca a senhora Jandira: “Parece que tem como ter um projeto e daí ter bolsas. Acho que é uma coisa assim [...]”.

A atuação da ONG se inicia com a contratação de um dos membros do grupo que passou a ser assalariado e responsável pela organização da rotina de produção da horta. Assim, altera-se a organização interna do grupo, visto que um dia eram companheiros de grupo e, no outro, se estabelece uma relação de subordinação entre esse "assalariado" e os demais membros do grupo, como evidenciado em fala da senhora Jandira: "Ontem a gente discutia junto, hoje você vai ter que obedecer?". Destaca-se, ainda, que ele era o único homem do grupo, o que reafirma a questão da relação de dominação de gênero.

Mais uma vez, ressalta-se a reafirmação dos pressupostos psicossociais da exclusão, restabelecendo-se hierarquias e processos pautados na heteronomia (GUARESCHI, 2002). Essa nova situação acentuou os conflitos no grupo e culminou com o afastamento do membro que havia sido contratado. 
Outra intervenção da ONG foi a designação de um técnico (vinculado à prefeitura) que seria responsável pelas decisões técnicas e produtivas da horta, o que não se efetivou visto que ele nunca compareceu à horta. Ressalta-se que a existência, apenas em promessa, dessa figura fez com que não procurassem ajuda técnica por outros meios, o que resultou em progressivo afastamento do grupo dos processos decisórios e técnicos de seu trabalho. Isso os desarticulou e fortaleceu as expectativas assistencialistas, isentando-os de uma postura mais ativa no processo de geração de trabalho e renda. Reinstalou-se o trabalho fragmentado e a alienação dos sujeitos. Portanto, foram práticas que tiveram um efeito oposto ao proposto pela Anteag (2005), de que todos os trabalhadores do empreendimento fossem responsáveis pelo mesmo, com uma visão organizacional estratégica do negócio e com o campo político.

Contudo, após poucos meses, a frequência de membros da ONG reduziu-se drasticamente, até se extinguir sem explicações ao grupo, o que gerou grande revolta, como expressa a senhora Margarida: “O pessoal da ONG sumiu e não deixou endereço. Ninguém sabe o que se deu deles. E a gente ficou sem saber e sem rumo." Entretanto, os efeitos desse afastamento podem ser considerados positivos, ainda que não permanentes e solidificados, pois os membros do grupo reavaliaram criticamente a atuação da ONG e reafirmaram a necessidade de autonomia, reassumindo, mesmo que temporariamente, os rumos do empreendimento.

O caráter perverso, apontado por Montaño (2002), na atuação de algumas organizações do Terceiro Setor também foi vivenciado pela Associação de Catadores que foi procurada por uma ONG, com sede no Rio de Janeiro. A partir dessa relação, a ONG disse que eles poderiam conseguir equipamentos e benefícios se comprovassem a produção e a colaboração que exerciam para o meio ambiente, o que pode ser comprovado pela fala da senhora Kátia: "Eles disseram assim: quando vocês conseguirem provar que produzem um tanto, vamos conseguir para vocês coisas que vocês precisam."

Essa comprovação viria pela entrega de cópias das taras de produção (documento de registro dos materiais separados e vendidos) e, quando atingissem um volume de produção adequado (nunca explicitado qual era), receberiam benefícios. A fala do senhor 
Joaquim explicita isto: "Ela diz que a gente tá quase chegando no que precisa pra ganhar, que falta comprovar que produziu só mais um pouco."

Dessa relação, a associação recebeu apenas um computador ultrapassado e com poucas condições de uso. Quando a representante da ONG foi questionada sobre os reais usos das taras recolhidas todos os meses, ela não conseguiu explicar com clareza. Foi solicitado a ela que apresentasse o contrato assinado, e a mesma não o mostrou, apresentando apenas o contrato com associação de catadores da região. Este era lacônico, apresentava as possibilidades de benefícios e o dever da Associação em fornecer as taras que comprovavam a produção, mas não explicitava o compromisso da ONG com a Associação.

Descobriu-se, então, que a mesma estava vinculada a uma grande empresa multinacional, sendo que tanto a ONG, quanto a empresa precisavam apontar indicadores de colaboração com a logística reversa e, portanto, com projetos de reciclagem em atendimento, por exemplo, à Política Nacional de Resíduos Sólidos, Lei 12.305 (BRASIL, 2010a). Após as solicitações de explicações e do contrato, a representante da ONG nunca mais compareceu à Associação e não devolveu as taras que tinham sido retidas.

\section{Representação acerca das funções que seriam próprias de cada agente}

A partir da análise da trajetória e dinâmica dos grupos e da relação destes com outros agentes, destaca-se a força do ideário assistencialista, presente nas ações de todos os sujeitos dos processos, o que turvava a compreensão de que esses se constituíam sujeitos de direitos e que o acesso ao trabalho e à renda deveria ser conquistado pelos mesmos e garantido através de Políticas Públicas, que são respaldadas por: criação da Senaes; PNRS (BRASIL, 2010a) e Programa Pró-Catador (BRASIL, 2010b), especificamente, para grupos de catadores de resíduos sólidos. Mesmo com a institucionalização de secretarias, políticas e programas, em âmbito nacional, observa-se a dificuldade de efetivação de ações pró EES por parte do Poder Público Municipal.

Verifica-se, também, a dificuldade de ruptura com o modelo assistencialista expressada intimamente nas representações acerca de quais seriam as funções cabíveis a cada segmento (grupo, universidade, Poder Público). Assim, mantinha-se uma relação em 
que os grupos deveriam receber e responder de forma positiva e agradecida as ofertas propiciadas pelos agentes externos. A fala da senhora Jandira aponta nesse sentido: “Ah... acho que a função deles [Poder Público Municipal] era ajudar a gente, né? Tem muita coisa que a gente precisa." No mesmo sentido, tem-se a fala de um assessor do Poder Público Municipal: “A prefeitura ajuda naquilo que pode, né? Agora vai deles trabalharem e fazer o negócio crescer." Esse posicionamento constituía-se em um dificultador para o clarear o efetivo papel e função de cada agente, bem como dos membros do grupo como cidadãos de direitos.

Destaca-se, ainda, a falta de clareza na relação com a Universidade, afinal: que tipo de apoio seria esse? Qual é o interesse? Quais seriam os balizadores dessa relação? A fala do senhor Geraldo indica para isso: “Então, vocês ajudam a gente a organizar as coisas.”

\subsection{Apropriação dos princípios da economia solidária}

\section{Associação de Catadores}

Na Associação de Catadores, o coletivo destacava a gestão como algo associado exclusivamente à produção, ou seja, relacionado às atividades de produção, realizadas na esteira, na baia, na prensa, dentre outros. Destaca-se que as atividades administrativas (gestão) não eram percebidas como trabalho e, portanto, o tempo despendido com essas atividades era significado como desperdiçado, não contribuindo para a geração de renda da Associação. Desta feita, não consideravam como gestão as atividades relativas às funções estatutárias, dentre elas as do Conselho Fiscal, nem as reuniões semanais, entre o grupo, para tomada de decisão ou prestação de contas.

Assim, essas atividades eram esquecidas e não consideradas como relevantes para a manutenção das ações e dos resultados econômicos, como mencionado pelo senhor Genival: “Não é justo eu ficar na esteira em pé e no calor, enquanto outro está sentado e com ventilador para ficar fazendo conta."

Mesmo com a definição de autogestão ("a ação coletiva de tomar decisão, fazendo reuniões para discussão e trabalhando igualmente") pelo próprio grupo, as decisões eram de três associados, visto que as reuniões eram realizadas, principalmente, quando as pessoas do Projeto de Extensão compareciam, segundo os demais associados. 
Os associados justificavam essa dificuldade, para a organização democrática dos processos deliberativos, pela diferença de alfabetização e conhecimentos escolares entre eles. Guareschi (2002) posiciona a exclusão dos saberes como um dos pressupostos psicossociais da exclusão, ou seja, a exclusão do saber da língua escrita e de outros saberes formais gera outras exclusões e a manutenção de relações de subserviência.

O grupo compreendia o que era autogestão, o que não significava a sua apropriação como práxis, o que seria fundamental, pois possibilitaria o desenvolvimento humano e do grupo "rompendo as dissociações entre teoria e prática, em cada uma e em todas as modalidades em que elas podem ocorrer" (BLEGER, 1998, p. 72).

Destaca-se que a interiorização da autogestão se tornava mais complicada, pois os associados vivenciaram outras experiências de trabalho, com predomínio da heterogestão. Assim, fazia-se necessário quebrar o costume de simplesmente seguir metas e objetivos que muitas vezes não contavam com a participação do sujeito e que não eram significativos para eles. Os associados careciam não só compreender, mas internalizar que o coletivo define as regras e metas, pois ninguém melhor do que os próprios sujeitos, no processo de organização do trabalho, para identificar as dificuldades, assim como as formas de superá-las e qual caminho tomar. Caçando e Caçando (2009, p. 59) apontam neste sentindo, ao identificarem que a heterogestão está enraizada e que a autogestão não nascerá naturalmente, sendo "necessário um trabalho, junto aos grupos que pertencem aos EES, para possibilitar a construção da autogestão."

Contudo, a intervenção do Poder Público fortaleceu a heterogestão e o centralismo em detrimento da autogestão, como expresso nesta fala: "pessoas que não eram capazes de se auto-organizar e gerir, precisando sempre de alguém que fosse realmente capaz de avaliar as situações e tomar as decisões por eles".

Uma característica da relação de parte dos associados com o trabalho e a Associação era a alta rotatividade, pois muitos dos sujeitos não a viam como seu local de trabalho e geração de renda permanente, ou como local que melhoraria a sua condição de vida, mas sim como uma ocupação provisória e, portanto, desvinculada de sua vida 
social. Entendiam que "era um trabalho temporário até conseguir uma coisa melhor" (Rute).

Com isso, a formação e a vivência desses em um grupo autogerido era prejudicada, bem como os demais princípios da Economia Solidária. Assim, manteve-se, de certa maneira, a reprodução dos processos de alienação vivenciados em empresas capitalistas, como observado na fala do senhor Riovaldo: "Prefiro patrão, depender da consciência do outro não dá certo." A figura do patrão era vista como alguém que detém maior conhecimento sobre o trabalho executado e que possui maior grau escolar, apto a resolver os problemas e tomar decisões para o bom desenvolvimento do trabalho. Nesse sentido, reforça-se que o processo de alfabetização do grupo é de suma importância para a emancipação dos sujeitos e desenvolvimento do coletivo (VERARDO, 2005).

Para os associados, só uma pessoa poderia ser "patrão", devido à sua liderança e ao seu grau de escolaridade, o que lhe conferia "entendimento maior do processo produtivo". O grupo a legitimava, mesmo sendo esta do sexo feminino. Esse "poder concedido" fez com que ela ultrapassasse os limites de sua função, como presidente, negligenciando o poder de decisão da Assembleia. Observa-se que essa relação entre a presidente e o grupo reproduzia e recriava a relação patrão/empregado, vivenciada por eles em suas histórias de vida e trabalho, como ressaltado por Singer (2008).

Esse centralismo foi problematizado pelo grupo, o que resultou em participação de outros associados tomando a palavra nas reuniões, o que foi viabilizado por trabalhos em subgrupos, garantindo liberdade aos associados em darem suas opiniões. Contudo, como discutido em tópico anterior, esse aprendizado e a compreensão e apropriação de ferramentas de controle financeiro e gestão, o que também foi trabalhado com o grupo, foram avanços arrefecidos por intervenção do Poder Público Municipal.

Assim, depreende-se que a autogestão e os demais princípios da economia solidária precisam ser constantemente trabalhados e experienciados pelo grupo. As principais barreiras que dificultam esse processo são: vivência do trabalho organizado sob a lógica do modo de produção capitalista; interferências externas na gestão; baixo nível 
de escolaridade; e alta rotatividade de pessoas no grupo. Esses pontos também são destacados por Coutinho et al. (2005), Verardo (2005), Singer (2008) e Baptista (2013).

Estes dificultadores foram entraves para que se construísse uma cultura própria, em que os conceitos estivessem bem estruturados e interiorizados (ANTEAG, 2002). Com isso, o Conselho Fiscal, os cargos administrativos e a Assembleia não realizavam suas obrigações como descritas no Estatuto Associação, fazendo com que se estabelecesse uma lacuna entre a atuação ideal e correta e aquela que se efetivava.

\section{Grupo Horta}

A forma de organização inicial do grupo (projeto de autoria de um médico do Ambulatório DST/AIDS e ligado à Prefeitura Municipal) construiu marcas profundas, expressas em sua trajetória de dependência de agentes externos, como relato da senhora Rosa: "O Dr. fez o projeto e ganhou o prêmio que dava bolsas pra gente, depois as bolsas terminaram, mas seria bom mesmo se ele tivesse conseguido de novo." Verardo (2005) também destaca o problema de atos decisórios não serem democráticos e, sim, tecnocráticos, como algo prejudicial para a autogestão.

Essa dependência, também, estava atrelada aos processos de exclusão e de relação de caráter assistencialista vivenciados pelos sujeitos com o poder público e outras instituições. Outro agravante é a vivência social de preconceito por terem o HIV, o que está, historicamente, associado a grupos sociais marginalizados (prostitutas, homossexuais e usuários de drogas), sendo ora "vítimas" ora culpados pelo seu adoecimento (ALMEIDA; LABRONICE, 2007). Esse preconceito social, em relação aos portadores do HIV, pôde ser observado quando os moradores do bairro organizaram um abaixo-assinado para que a horta não fosse construída, pois o local era tranquilo e passaria a ter a presença de drogados e prostitutas. Essas representações pejorativas participam da constituição da autoimagem dos sujeitos de forma estereotipada, como se nota na fala da senhora Jandira: “De tanto ser tratada assim, a gente acaba acreditando que é bicho mesmo. Já espera o preconceito e estranha quando é diferente."

Segundo Guareschi (2002), no processo de legitimação da exclusão é necessário que se encontre uma "vítima" expiatória na qual recai e se descarrega a discriminação. 
Essa "vítima" é o próprio excluído, que é representado como um indivíduo que constrói a si próprio, independente das condições materiais de existência. Destarte, cria-se uma justificativa apartada das relações sociais excludentes em que o mesmo está engendrado, como apontado em Nascimento (1994, 2000). Tais justificativas atribuem a causa da exclusão a características e/ou comportamentos dos próprios sujeitos que as enfrentam.

A vivência da discriminação os fez significar a condição de exclusão como inexorável, não se reconhecendo como sujeitos de direitos, mas sim aqueles que podiam receber pequenos benefícios “dados por órgãos governamentais e não governamentais" e que deviam, portanto, se "contentar" com isto (PERES, 2002; BAPTISTA, 2013).

Assim, qualquer proposta de promoção da autonomia deve atentar ao histórico dessas pessoas e possibilitar a ruptura com o socialmente instituído. Isso depende de um processo de reconstrução de imagem, relações e significados. Os agentes apoiadores também são atravessados por essas representações socialmente constituídas e, portanto, há a chance de reproduzi-las. Então, faz-se necessário que os apoiadores reconheçam essa dinâmica e possam ser favorecedores das reflexões grupais. Para tal, precisam superar a posição de "externos" para se colocarem em uma condição de aprendizagem contínua e conjunta com o grupo, o que não se efetivou.

Assim, observaram-se as dificuldades de rupturas do grupo, expressas pela negação em assumir os processos de tomada de decisões. Estas eram assumidas, em muitos momentos, por uma pessoa do grupo, o que era significado negativamente pelos demais componentes do grupo: "ele(a) quer mandar". Esse funcionamento remetia à presença constante de bodes-expiatórios - integrantes do grupo que eram representados pelos demais como responsáveis por problemas vivenciados pelo grupo (GAYOTTO, 1996). Atribuíram-se os papéis de liderança aos membros do programa de saúde e da Prefeitura que, por sua vez, não raramente, os assumiam e reforçavam a heterogestão, resolvendo problemas e decidindo por eles. Isso vai de encontro com Verardo (2005) e Caçando e Caçando (2009), pois dificultou o processo de autossuficiência e a possibilidade de se reconhecerem capazes de prover, a si e aos seus, sem a necessidade de programas assistencialistas como o próprio projeto, em alguma medida, se constituiu. 
Dessa forma, a questão da geração de renda e a sistematização da produção ficaram comprometidas, indicando que não foram assumidas enquanto sentidos para o grupo, assim como pelos agentes públicos.

\section{Associação de Mulheres Artesãs}

No início do grupo, as mulheres foram resistentes em se apropriarem da gestão do empreendimento e dos saberes para tal. Alegavam um não saber e percebiam isso como algo que dificilmente seria superado. Destaca-se, novamente, o apontado por Guareschi (2002) sobre os processos sociais de exclusão, em que o excluído se culpabiliza pela situação precária em que vive, como apontado pela senhora Rosana: "Minha cabeça não dá pra isso." Elas se mantinham como detentoras do saber produzir, mas não do saber administrar, repassando isso aos Universitários, como relatado pela senhora Rosana: "Quem estuda pra isso, faz isso melhor. É mais seguro."

Ao longo do trabalho, construíram-se ferramentas adequadas de gestão, em parceria com as mulheres. Contudo, insistiam em centralizar essa função na integrante mais nova, por ter mais anos de estudos. Com o tempo, passaram a compreender os processos, mas continuaram temendo realizá-los e responderem pelos mesmos.

Há uma apropriação da marca e mais efetiva da produção, pois elas se organizaram para atender as encomendas e criar novos produtos, como referência da senhora Julieta: "A gente tem a nossa marca. A gente sabe controlar o que compra, vende, quanto cada coisa custa e que não vale a pena fazer."

Dos grupos acompanhados, pode-se dizer que foi este o que permaneceu por mais tempo funcionando de forma mais autogestionada, havendo cooperação entre elas e viabilidade econômica do grupo como salientado por Coutinho et al. (2005) e Singer (2008). Além disso, foi o único grupo que se formou por decisão delas, visto que os outros dois foram idealizados e estimulados por agentes externos. 


\section{Conclusões}

Os três grupos eram compostos por trabalhadores (baixa escolaridade e formação profissional e limitação física, por causa de idade, doenças e convivência com o HIV) com experiências de trabalhos formais (carteira assinada) e que, ao perderem seus empregos, não conseguiram se reinserir no mercado. Assim, essa busca pelos grupos não se deu por uma prévia identidade aos princípios da Economia Solidária, mas sim pela possibilidade de trabalho e renda. Ao contrário disso, traziam como sonho "recuperar a condição de trabalhadores registrados no mercado formal", o que os fazia reclamar da ausência de um patrão e, inclusive, do controle feito pela sirene das fábricas em seus ritmos e tempos.

A dinâmica dos três grupos atrela-se à condição como estes surgiram e foram assessorados pela extensão universitária e relação com Poder Público Municipal. A formação dos grupos, a união das pessoas e a organização destes, não foi espontânea. Ao invés disso, contaram com a ação de agentes "catalisadores", como o Poder Público, as ONG ou os profissionais da saúde. Então, os projetos existiram antes na prospecção desses agentes e depois foram incorporados e transformados pelos grupos. A decisão de vinculação a esses grupos (ESS), de geração de renda, deve-se à falta de opção, mas também à identificação de oportunidade para experimentar essa nova experiência apresentada. Essa vinculação dependia da aproximação com os princípios da Economia Solidária, o que foi gradual e não linear, visto que houve períodos de afastamentos dos pilares fundamentais às propostas economicamente solidárias.

A dificuldade de apropriação dos princípios da Economia Solidária se deve ao viés assistencialista que permeou a ação e relação de todos os agentes. Pode-se dizer que a compreensão do trabalho e da renda como direitos não se consolidou, seja pelos integrantes dos grupos, seja pelos agentes externos, inclusive o Poder Público Municipal. Desta forma, a incorporação dos princípios da Economia Solidária foi um desafio que em poucos momentos foi contemplado. $\mathrm{O}$ afastamento se dava pela falta de clareza quanto à função de cada agente e da construção efetiva de metas e projetos coletivos.

Dos princípios da economia solidária, a autogestão, a tomada coletiva de decisões, a apropriação do conhecimento sobre os processos de produção e a gestão foram mais 
observadas na Associação de Artesãs, pois não foi impactada por ingerência (diferentemente dos outros dois grupos) por parte do Poder Público Municipal. A atuação deste não colaborou para o desenvolvimento dos outros dois grupos, visto que sua atuação era um dificultador em muitos momentos. Ressalta-se a ausência de políticas públicas destinadas à geração de trabalho e renda, dentro dos princípios da Economia Solidária, e o predomínio de ações assistencialistas e clientelistas. Quanto à Universidade, sua posição nem sempre foi clara, por vezes reproduzindo práticas instituídas e, em outros momentos, favorecendo rupturas. Com isso, a relação entre grupos, Poder Público e Universidade não foi linear, pautada por contradições, disputas e desarticulação, o que resultou em mais limites do que potencialidades.

A viabilidade econômica dos empreendimentos, com destaque para a comercialização, é um princípio da Economia Solidária fundamental para os empreendimentos, pois garante a consolidação destes e, portanto, a renda de seus trabalhadores. No entanto, esse princípio compareceu como um dificultador para a consolidação destes. O isolamento dos grupos, sem articulação em uma rede e/ou cadeia, contribuiu para a vulnerabilidade econômica dos empreendimentos, ficando suscetíveis às variações de mercado e produção. A criação e consolidação de canais de comercialização foi um desafio enfrentado e respondido isoladamente por cada um dos grupos, contudo, nenhuma das estratégias foi considerada satisfatória. Dessa forma, a inconstância da renda constituía-se em dificuldade, visto as significativas oscilações.

A análise dos casos aponta elementos importantes em que o trabalho autogestionado favorece certa superação de condições de alienação e adoecimento, tantas vezes denunciadas em empreendimentos que priorizam o lucro. Destaca-se que foi, justamente, a primazia do lucro que promoveu processos de adoecimento de vários integrantes dos grupos, excluindo-os do mercado formal.

Salienta-se que o processo de emancipação dos sujeitos, quando ocorre, dá-se por: seu reconhecimento no produto do seu trabalho; desenvolvimento de laços cooperativos, que são elementos fundamentais para a promoção de condições de uma vida saudável e com qualidade; e consolidação de um empreendimento em Economia Solidária. Ressaltam-se, ainda, os impactos dessas transformações na autoestima dos 
trabalhadores para que se sintam mais capazes de superar as condições que enfrentam.

Esta configuração também resulta em redução da vulnerabilidade social dos grupos, pois constitui uma rede de apoio mútuo para momentos de crise, o que contribui para firmar o princípio de solidariedade. Para além da renda em espécie, essa rede de apoio merece destaque na promoção do cuidado e amparo dos membros em situações de crise.

Assim, as condições estruturais do trabalho e a premência pela geração de renda (garantia da subsistência), constituem-se como elementos que ameaçam a vivência no trabalho de forma mais saudável. Portanto, é um ponto nevrálgico a ser superado, para que os princípios da Economia Solidária se concretizem nos empreendimentos.

Por fim, a partir dessas experiências, alguns elementos devem ser considerados para que se estabeleça uma relação mais exitosa e efetivamente compromissada, propiciando a emancipação dos sujeitos e o desenvolvimento dos empreendimentos. Primeiro, destaca-se a necessidade de se considerar os sujeitos concretos (trajetórias, vivências e percepções), bem como as representações socialmente constituídas que compõem sua autoimagem e, portanto, seu posicionamento frente ao próprio trabalho e ao mundo. Segundo, tem-se que buscar a integração de 'aspectos emocionais envolvidos no desenvolvimento dos grupos' com a 'apropriação de conhecimentos técnicos e acadêmicos' (formação básica - leitura, cálculo e escrita e ferramentas de gestão), para que se promova a autogestão. Terceiro, deve-se estimular a participação efetiva dos sujeitos, desde a decisão de constituição dos grupos, pois a origem parece os acompanhar ao longo de toda sua trajetória, favorecendo ou dificultando o processo de empoderamento dos sujeitos.

Além disso, como quarto elemento, há a necessidade de entender o grupo como um espaço dialético, em que podem ser reproduzidas relações de exclusão e dominação, mas que ao serem reconhecidas e explicitadas, podem também ser transformadas. Assim, tem-se como relevante quinto elemento, reconhecer os limites de atuação de cada agente do processo, em que se evidencia a necessidade de formação contínua desses ao longo do trabalho, para que não se estabeleça condição de privilégio e reproduza práticas de exclusão e socialmente instituídas. 
Como sexto elemento, tem-se a busca contínua de compreensão do processo de trabalho pelo grupo, bem como das relações institucionais e políticas que o atravessam. E, assim, por fim, destaca-se a relevância da atuação do Poder Público, fomentando políticas de ruptura ao assistencialismo e clientelismo e viabilizando a Economia Solidária, como proposta concreta de geração de trabalho e renda.

Mesmo diante desses elementos, que deveriam ser considerados nos grupos e nas suas relações com agentes externos para a consolidação dos empreendimentos, observam-se avanços nos grupos analisados. Ressalta-se o quanto podem ser efetivas relações realmente articuladas na direção das transformações sociais. Assim, os limites dessa experiência apontam para as possibilidades de êxito dos trabalhos dentro da perspectiva da Economia Solidária. Destarte, qualquer proposta de promoção da autonomia, deve atentar-se ao histórico do projeto e dos sujeitos, além de almejar a ruptura. É, portanto, um processo que visa reconstruir relações e significados, em que o grupo é um espaço privilegiado para o aprendizado.

\section{Referências}

ALMEIDA, Maria Rita de Cássia Barreto de; LABRONICI, Liliana Maria. Trajetória silenciosa de pessoas portadoras do HIV contada pela história oral. Revista Ciência e saúde coletiva, Rio de Janeiro: Abrasco, v. 12, n. 1, p. 263-274, 2007.

ALVES, Alda Judith. O Planejamento de pesquisas qualitativas em educação. Cadernos de Pesquisa, São Paulo: Fundação Carlos Chagas, v. 77, p. 53-61, 1991.

ANTEAG - Associação Nacional de Trabalhadores e Empresas de Autogestão. 2002, Economia solidária e democracia. In: SEMINÁRIO ECONOMIA POPULAR SOLIDÁRIA NO FÓRUM SOCIAL MUNDIAL, 2002. Porto Alegre. Disponível em: http://www.fbes.org.br /index.php?option=com_docman\&task=doc_download\&gid=1101\&ltemid=194. Acesso em: maio 2011.

ANTEAG - Associação Nacional de Trabalhadores e Empresas de Autogestão. Autogestão e Economia Solidária: uma nova metodologia. São Paulo: ANTEAG, 2005. 
ANTUNES, Ricardo. Adeus ao trabalho?: ensaio sobre as metamorfoses e a centralidade no mundo do trabalho. São Paulo: Cortez, 2002.

BAPTISTA, Vinícius Ferreira. Perspectivas e limites das políticas públicas voltadas à coleta seletiva de resíduos sólidos urbanos: análise a partir da política nacional de resíduos sólidos e de gestores de cooperativas de catadores de materiais recicláveis no Município do Rio de Janeiro. 2013. Dissertação - (Mestrado em Políticas Públicas e Formação Humana) Universidade Estadual do Rio de Janeiro. Rio de Janeiro, 2013.

BLEGER, José. Temas de psicologia: entrevistas e grupos. São Paulo: Martins Fontes, 1998.

BRASIL. Decreto n.7.405, de 23 de dezembro de 2010. Diário Oficial [da] República Federativa do Brasil, Brasília, DF. 2010b. Disponível em: https://www.planalto.gov.br /ccivil_03/_ato2007-2010/2010/decreto/d7405. Acesso em: 12 março de 2017.

BRASIL. Lei n 12.305, de 2 de agosto de 2010. Diário Oficial [da] República Federativa do Brasil, Brasília, DF. 2010a. Disponível em: http://www.planalto.gov.br/ccivil_03/_ato 20072010/2010/lei/l12305.htm. Acesso em: março de 2017.

BRASIL. Lei n 13.467, de 13 de julho de 2017. Diário Oficial [da] República Federativa do Brasil, Brasília, DF. 2017. Disponível em: http://www.planalto.gov.br/ccivil_03/_ato20152018/2017/lei/l13467.htm. Acesso: fevereiro de 2017.

BRASIL. Ministério do Trabalho e Emprego. Secretaria Nacional de Economia Solidária. Atlas da economia solidária no Brasil, 2005. Brasília, 2006. Disponível em: http://www.mte. gov.br/empregador/economiasolidaria/conteudo/atlas.asp. Acesso em: junho de 2014.

BRASIL. Ministério do Trabalho e Emprego. Secretaria Nacional de Economia Solidária. Atlas da Economia Solidária no Brasil, 2013. Brasília, 2013. Disponível em: http://sies.ecosol.org.br/atlas. Acesso em: 20 set 2016.

CAÇANDO, Airton Cardoso; CAÇANDO, Anne Caroline Moura Guimarães. A Construção da Autogestão em Empreendimentos da Economia Solidária: uma abordagem baseada em Paulo Freire. REGES - Revista Eletrônica de Gestão, Picos, PI: UFPI, v. 2, n. 2, p. 56-72, 2009.

CASTANHEIRA, Maria Eugênia Monteiro; PEREIRA, José Roberto. Ação coletiva no âmbito da economia solidária e da Autogestão. Psicol. estud. [online], Maringá, PR: UEM, v. 13, n. 4, p. 703-711, 2008. 
COUTINHO, Maria Chalfin; BEIRAS, Adriano; PICININ, Dhiancarlos; LUCKMANN, Gabriel Luiz. Novos caminhos, cooperação e solidariedade: a psicologia em empreendimentos solidários. Psicologia e Sociedade, Porto Alegre, RS: UFRGS, v. 17, n.1, p. 141-156, 2005.

FRANCO, Maria Laura P. Barbosa. Análise de conteúdo. Brasília: Líber Livro, 2002.

GAYOTTO, Maria Leonor Cunha. Líder de mudança e grupo operativo. Petrópolis, RJ: Vozes, 1996.

GUARESCHI, Pedrinho A. Pressupostos psicossociais da exclusão: competitividade e culpabilização. In. SAWAIA, Bader. As artimanhas da exclusão: análise psicossocial e ética da desigualdade social. Petrópolis, RJ: Vozes, 2002. p. 141-156.

HAMMERSLEY, Martyn; ATKINSON, Paul. Etnography: principles em pratice. 7. Ed. London: Routledge, 1992.

LUDKE, Menga; ANDRÉ, Marli E. D. A. A pesquisa em educação: abordagens qualitativas. São Paulo: EPU, 1986.

MATHEUS, Tiago Corbisier. Individualismo e desejo contraditório na formação de grupos. In: MOTTA, Fernando Claudio Prestes; MOTTA, Maria C. Cintra do Prado Prestes; FREITAS, Maria Ester. Vida psíquica e organização. Rio de Janeiro: Editora FGV, 2000. p. 117-129.

MONTAÑO, Carlos. Terceiro Setor e questão social. São Paulo: Cortez, 2002.

PERES, Wiliam Siqueira. Biossociabilidade contemporânea e a expressão travesti. Revista de Psicologia da UNESP, Assis, SP: UNESP, v. 1, n.1, p. 8-17, 2002.

NASCIMENTO, Elimar Pinheiro do. Hipóteses sobre a nova exclusão social: dos excluídos necessários aos excluídos desnecessários. Cadernos CRH, Salvador, n. 21, p. 29-47, 1994.

NASCIMENTO, Elimar Pinheiro do. Dos excluídos necessários aos excluídos desnecessários. In: BURSZTYN, Marcel (Org.). No meio da rua. Rio de Janeiro: Garamond, p. 56-85, 2000.

SANTOS, Tania Steren dos. Globalização e exclusão: a dialética da mundialização do capital. Sociologia, Porto Alegre, n. 6, p. 170-198, 2001.

SILVA, Rosalina Carvalho. Metodologias participativas para trabalhos de promoção de saúde e cidadania. São Paulo: Vetor, 2002. 
SINGER, Paul. Entrevista com Paul Singer: Economia Solidária. Revista de Estudos

Avançados, São Paulo: IEA/USP, v. 22, n. 62, p. 289-314, 2008.

SINGER, Paul. Dez anos de Secretaria Nacional de Economia Solidária (SENAES). Ipea, Mercado de Trabalho, ano 20, n56, p. 89-94, 2014.

VERARDO, Luigi. Construindo autogestão e parceria solidária. In: MELLO, Sylvia Leser (Org.). Economia Solidária e Autogestão: Encontros Internacionais. São Paulo: PW Gráficos e Editores, 2005.

Recebido em: 15/02/2018 Aprovado em: 22/11/2018

Universidade do Estado de Santa Catarina - UDESC Centro de Ciências Humanas e da Educação - FAED

Revista PerCursos Volume 19 - Número 41 - Ano 2018 revistapercursos@gmail.com 